\title{
CONSUMER PREDISPOSITION AND BEHAVIOR TOWARDS MOBILITY-AS-A-SERVICE AMONG UNIVERSITY STUDENTS IN A DEVELOPING COUNTRY
}

\author{
RODRIGO MARÇAL GANDIA ${ }^{1,2,3}$, JULIA R. OLIVEIRA ${ }^{4}$, FABIO ANTONIALLI ${ }^{1,2,3}$, \\ JOEL YUTAKA SUGANO ${ }^{2,3}$, ISABELLE NICOLAÏ ${ }^{1} \&$ IZABELA R. CARDOSO OLIVEIRA $^{4}$ \\ ${ }^{1}$ Laboratorie Génie Industriel (LGI), CentraleSupélec, Gif-sur-Yvette, France \\ ${ }^{2}$ Post-Graduate Program in Administration (PPGA), Universidade Federal de Lavras, Brazil \\ ${ }^{3}$ Terrestrial Mobility Laboratory (LMT), Universidade Federal de Lavras, Brazil \\ ${ }^{4}$ Department of Statistics (DES), Universidade Federal de Lavras, Brazil
}

\begin{abstract}
Mobility-as-a-Service (MaaS) has been recently gaining ground, presenting a shift away from existing ownership-based transportation and towards access-based ones. MaaS is still surrounded by uncertainties: its development and applicability are mainly centered in developed countries; however, we believe that MaaS is modular, adaptable and applicable to several realities. In this sense, this study aims to examine university student's demand and predisposition for MaaS usage in a developing country, as well as to understand the differences in mobility perception among those students who are car users and non-car users. This survey was applied to over 300 university students in a Brazilian city, Lavras. Using the CART algorithm, we obtained classification trees to predict favorable responses related to MaaS use, based on several predictor variables (socio-economic characteristics, means of transport used, distance, etc.). We observed that car users are a little less sensitive to cost than non-car users. For car users, the commute alternatives that take longer, with less flexibility and availability - even when offered at lower cost - are not appealing, while the non-car users accept alternative options and expend more time when lower costs are available. Also, in general, a tree-based classification model predicted a positive adherence possibility for a MaaS scheme for both car users and non-car users $(69 \%)$. As conclusions, this study suggests that there is a predisposition to accept the MaaS model for creating value for commuters in a developing country. We found that many MaaS characteristics (e.g. payment via app, transportation integration, monthly plan, customization, and so on) presented a positively predictable possibility of substitution, especially for Millennials. Also, we found that bicycles may be a mode that can be explored for Maas schemes worldwide, and that hitchhiking could be used as a strategy to apply MaaS in places where public transportation lacks efficiency.
\end{abstract}

Keywords: college students, developing countries, Mobility-as-a-Service, public transportation, travel behavior, university students, urban mobility, tree-based classification model.

\section{INTRODUCTION}

Over the course of the 20th century, private cars have become the dominant mode of transportation worldwide, due to their capacity of fulfilling the growing need for individuality, independence and flexibility; however, such private vehicles are also the source of a variety of negative environmental impacts, both on a global and local level [1]-[4]. Thus, urban mobility is suffering due to a rapid increase in vehicle numbers; hence, now the challenge is to enhance mobility and accessibility, while at the same time, reducing congestion, road accidents and pollution in cities. Therefore, the realization of more environment-friendly transportation systems is now a worldwide goal [5], [6]. As an alternative, shared mobility has the potential to reduce private vehicle dependence and by consequence, their negative environmental effects [7]-[9]. 
By presenting a shift away from the existing ownership-based transport system toward an access-based one, the concept of Mobility-as-a-Service (MaaS) has been gaining ground: it is becoming a concrete market option [6], [10]-[12]. By placing commuters as central actors, MaaS aims to offer tailored-made on-demand integrated mobility solutions, based on such users' needs [6], [10], [13]-[15]. The concept, however, is still surrounded by ambiguities and uncertainties [10]. Furthermore, most of MaaS deployments are centered in developed countries with efficient transportation systems [10], [12]. On the other hand, we believe that MaaS is modular, adaptable and applicable to several realities. In this sense, an eventual MaaS user (in any given context) should perceive a level of value that surpasses that of vehicle ownership or any other utilized transport mode. Nevertheless, to date, insights in terms of the MaaS behavioral impacts or its future potential are very limited [16]. In addition, studies about consumer behavior and MaaS usage are still incipient, as well as the fact that research on MaaS in developing countries has not yet been found in the literature [17].

The early adopters of MaaS are expected to be comprised of younger generations (Gen-Z and Millennials), because of their commute patterns: flexible travelers, who combine different modes of transportation to make their trips [18]. Mostly current university and college students can be comprehended as belonging to Gen-Z or the Millennials; in this sense, it is important to understand that consumer acceptance of this group for personalized on-demand services like this, in order to comprehend whether MaaS can be achieved, from the consumer perspective, in a developing country.

Given the aforementioned, the following questions were raised as guidelines for the present study: Is there a demand predisposition for MaaS among university students from a developing country? Among these students, are there differences between private car owners and non-owners, towards MaaS? Which are the main characteristics of the transportation means that are valued by university students? This study aims to examine university students' demand and predisposition for MaaS usage in a developing country, as well as to understand the differences in mobility perception among students who are car users and non-car users.

Besides this introduction, our paper is structured as follows. Section 2 provides an overview of urban mobility, with highlights on the efforts that are being made towards access-based mobility, and also regarding consumer and travel behaviors. Section 3 presents our research methodology, explaining the necessary steps to perform and analyze the survey. Section 4 presents our results and discusses the proposed analysis by demographically describing the sample; then by analyzing users' importance given to transport mode choice; the role of multimodality instead of ownership; and last, the tree-based classification models utilized to understand users' predispositions towards Mobility-as-a-Service schemes. Finally, in Section 5, we present our concluding remarks, summarizing the study's main findings and highlighting the possibilities for future research.

\section{LITERATURE REVIEW}

\subsection{Urban mobility: from car-ownership to MaaS}

One of the biggest hurdles within urban transportation is car-dependency, especially in places where public transportation is not efficient [19], [20]. Thereby, the excessive number of automobiles has been pointed out as the main source of pollution and traffic congestion in urban centers, worldwide [21]; thus, today's mobility paradigm is reaching its environmental, economic and social limits, to a point that the privately owned car will be more and more challenged as a solution to satisfy mobility needs [22]. Thus, efficient urban mobility is unlikely to be achieved without the provision of efficient, extensive and accessible 
multimodal transport options [6], [23]. In this sense, the concept of MaaS has been gaining ground and it is becoming a concrete market option. The core idea behind MaaS is to envision urban transport as a single service available on-demand and that incorporates all of a wide range of transport modes, from cars to buses, to rail [6]. In short, to present a shift away from ownership-based transport systems toward an access-based one [6], [10]-[12].

MaaS initiatives are fairly recent, and most of them resemble in scope the current models of flexible transport services, including demand responsive transit [16]. What is different, however, is the ability to bring such flexible options direct to users on a single app [24]. Nevertheless, the main issue with this value proposition is to integrate all transport means in order to provide a better transportation choice for users, from shared economy perspective.

We comprehend, moreover, that the issues go beyond connectivity and modal integration, and that a cultural shift is also necessary; one that aims at reducing private car dependency and trips made with fossil-fueled vehicles, towards multiple, often shared and public mobility offerings [11], [25]. However, such a task is easier said than done; in many cases, private cars entail utilities besides mobility. According to Steg [26], "car use not only fulfills instrumental functions, but also important symbolic and affective functions." In this sense, we understand the consumer and that travel behavior among car users and non-car users seems to be an interesting perspective of MaaS that can be analyzed.

\subsection{Consumer and travel behavior within urban mobility}

In terms of mobility, the choice for a given mode of transport is an indicator of an individual's commute consumption pattern, which is mainly guided by cost, time and comfort factors.

Private cars are very good at fulfilling the "comfort" requirement; and to some extent, "time," which makes it one the most suitable options for those who can afford it [27]. Complementary, as stated by Hans Arby (CEO of UbiGo) car ownership is a kind of "mobility insurance"; and therefore, represents flexibility and availability for its owners [28].

On the other hand, as pointed out by Delbosc et al. [29], some people would rather use their cars due to poor city infrastructures or inappropriate offers of alternatives modes of transport. Furthermore, as elucidated by Steg [26]; historically, car usage could be explained by instrumental factors such as speed, flexibility and convenience; however, the author states that symbolic and affective aspects also significantly influence the use of cars.

Nevertheless, younger generation cohorts (such as the Millennials and Gen-z) seem to prefer alternative modes of transport, when compared to previous generations; they are owning fewer cars, driving less, and making more use of other transport modes [29]. In this sense, they perceive mobility not as a "product" (a physical asset to be purchased, like a car) but as a "service" (available on-demand and with bundled transport offerings), seems to be congruent with these generations [6].

Even an industry as solid and consolidated as the automotive one, could suffer from a change of habits of a generation, as can be seen historically by the example of several consolidated industries that were disrupted by digitalization: Kodak vs. digital cameras; Blockbuster vs. Netflix; encyclopedia Britannica vs. Wikipedia; hotels vs. Airbnb, and so on [30]. With an expectation that MaaS will be adopted first by younger generations, it has the potential to disrupt the mobility industry on the same level as the aforementioned new business platform entrants disrupted traditional business models [18], [31].

In this sense, dematerialization practices [32] seem to be aligned with the consumption practices proposed by MaaS, with some pieces of evidence of this phenomenon already being observed. For instance, the results from UBIGO (MaaS operator in Stockholm) indicate an 
increase in the usage of sustainable transport modes, while the use of private cars was reduced by $50 \%$ [31], [33].

It is worth mentioning, however, that such positive MaaS results are derived from experiments carried out in developed countries and regions (with good city infrastructure and efficient transportation modes); thus, differing dramatically from the scope of implementation of MaaS proposed in this study. According to Delbosc et al. [29], travelers' behaviors are location-based; thus, the context in which mobility offerings are inserted matters. With that, it is not reasonable to believe that a given MaaS implementation will be effective in another reality, in a sense that, as stated by Datson [15]: "there will be no one model of MaaS that fits all".

\section{RESEARCH METHODOLOGY}

This study is characterized by having a quantitative and exploratory nature. The first step refers to data collection. The survey was applied to 307 university students in Lavras, Brazil enrolled in the second academic semester of 2018. This city of approximately 100,000 inhabitants was chosen as an object of study, given its peculiar mobility features. Due to the high number of university students who attend one of the four universities in the city, hitchhiking is commonplace on their daily commute.

Data collection was done by a cross-sectional study survey; with the application of a questionnaire among some students of the four higher education institutions (HEI) of the city (both public and private institutions). Participants were selected by non-probabilistic sampling [34]-[36]. The questionnaire used in data collection consisted mainly of qualitative questions. In addition to the characteristics of the individual, we investigated their motivations for choosing some transportation means and their predisposition for sharing.

After the data pre-processing the data, descriptive statistics were used and tree-based classification models were obtained. The latter was used while studying the profiles of users predisposed to demand MaaS. This classification tree technique was particularly useful when there were large numbers of predictor variables involved in the analysis. In this work, we used the CART algorithm [37] as implemented in the rpart.R package, followed by the plots obtained through the rpart.plot package.

\section{RESULTS AND DISCUSSION}

We collected a total of 307 responses. The average age range for car users was 25 years of age; while for non-users, it was 22 years of age. As for gender, numbers were similar for men and women (141 and 166 responses, respectively). As our sample comprised of university students, the majority of respondents were single (282), while only 22 were married and 2 were divorced.

\subsection{Importance of transport mode choice}

Table 1 depicts the benefits perceived by the users regarding the choice of a transport mode (depicted as columns) and the independent variables (depicted as lines) in a table. Such variables were analyzed in 5-point scales (ranging from 0 to 4 : from less important to most important) for each transport mode.

Compared to other transport modes, vehicle owners pointed out that they opted for this modality mostly because of its agility (3.83), flexibility (3.82), availability (3.73), security (3.60) and comfort (3.28); such results are congruent with the ones found by others [27], [28]. 
Table 1: Variable importance on the choice of transport mode by study participants.

\begin{tabular}{|c|c|c|c|c|c|c|c|c|c|c|c|c|}
\hline & \multicolumn{2}{|c|}{$\begin{array}{c}\text { Car } \\
\text { (as driver) }\end{array}$} & \multicolumn{2}{|c|}{$\begin{array}{c}\text { Car } \\
\text { (as passenger) }\end{array}$} & \multicolumn{2}{|c|}{ Walking } & \multicolumn{2}{|c|}{ Bus/Shuttle } & \multicolumn{2}{|c|}{ Motorcycle } & \multicolumn{2}{|c|}{ Bicycle } \\
\hline & Mean & $\mathrm{SD}$ & Mean & SD & Mean & SD & Mean & SD & Mean & SD & Mean & $\mathrm{SD}$ \\
\hline Agility & 3.83 & 0.494 & 3.69 & 0.467 & 2.73 & 1.423 & 2.89 & 1.191 & 3.86 & 0.434 & 3.00 & 0.816 \\
\hline Availability & 3.73 & 0.617 & 2.97 & 1.206 & 3.10 & 1.287 & 2.77 & 1.310 & 3.66 & 0.802 & 3.00 & 0.816 \\
\hline Care for health & 2.82 & 1.276 & 2.75 & 1.380 & 2.82 & 1.289 & 2.47 & 1.521 & 2.53 & 1.502 & 3.00 & 0.816 \\
\hline Comfort & 3.28 & 0.992 & 2.69 & 1.369 & 2.01 & 1.557 & 2.56 & 1.382 & 2.40 & 1.354 & 1.50 & 0.577 \\
\hline Cost & 2.38 & 1.350 & 3.16 & 1.183 & 3.08 & 1.531 & 3.13 & 1.036 & 3.53 & 1.041 & 3.50 & 0.577 \\
\hline Flexibility & 3.82 & 0.418 & 2.88 & 1.326 & 3.22 & 1.151 & 2.46 & 1.531 & 3.66 & 0.711 & 3.00 & 0.816 \\
\hline Parking difficulties & 2.80 & 1.280 & 1.86 & 1.690 & $\ldots$ & $\ldots$ & $\ldots$ & $\ldots$ & 3.43 & 1.040 & 2.75 & 0.957 \\
\hline Safety & 3.60 & 0.761 & 3.22 & 1.244 & 2.55 & 1.579 & 3.13 & 1.148 & 2.66 & 1.268 & 1.75 & 0.500 \\
\hline Status & 0.47 & 0.893 & 0.36 & 0.833 & 0.53 & 1.140 & 0.62 & 1.119 & 0.76 & 1.250 & 1.00 & 1.154 \\
\hline Sustainability & 1.78 & 1.438 & 2.19 & 1.489 & 2.85 & 1.149 & 2.72 & 1.247 & 2.13 & 1.547 & 3.00 & 0.816 \\
\hline Traffic avoidance & 2.70 & 1.030 & 2.36 & 1.220 & 2.38 & 1.629 & 2.28 & 1.400 & 3.40 & 0.968 & 3.00 & 0.816 \\
\hline
\end{tabular}

Although the cost per trip for car owners is the factor with the least repercussion among the other transport modes (2.38), it was observed that such average is not much higher than the ones of other transport modes, such as bicycles, buses, or even walking. This may be explained because, in general, car owners tended to consider only fuel costs when questioned about their commute costs, and forget to include the fixed costs and other additional expenses like insurances, taxes and depreciation. Thus, this can also be a complicating factor in attracting car owners to participate in MaaS schemes. For instance, Lyons et al. [16] concluded that the installment purchase of a Ford Fiesta and the monthly subscription to Whim (the MaaS scheme in Helsinki) would have very similar values.

On the other hand, regarding status, we observed that car owners do not value the fact of "being seen driving an automobile" as something important to them (0.47). This goes against the symbolic and affective propositions in the choice of modal proposed by Steg [26]. Such results may be explained due to the profile of the sample (university students belong to either the Millennials or Gen-Z) and their unique commute patterns regarding transport modes [29], which may lead to their motives to use a car as being more instrumental, rather than affective and/or symbolic.

On the other hand, the modal that presented the highest averages attributed to status was the bicycle (1.00), which may be linked to the assumption that bicycles incite health and sustainability-related benefits, which may be influencers of this perception of status. This can be supported by the fact that this modal presented the highest averages, regarding care for health and sustainability (both 3.00). In this way, bicycle is a modal that is still neglected in MaaS studies [31], but it is a one that holds great potential (especially for the first and last miles of the daily commute). Corroborating this, Mulley [11] states that the recognition of active travel commute (e.g., cycling) can play a fundamental role in pushing this modal towards MaaS.

The search for parking spaces stimulated by high urban density is another factor that may influence the predisposition towards MaaS [11]. We observed that motorcycle users are the most concerned about parking difficulties (3.43). In this sense, it is important to highlight that just as a lack of infrastructure can discourage the deployment of MaaS schemes, the opposite can also serve as a stimulus (as is the case of the provision of parking spaces). In a study carried out in Sweden on corporate MaaS (CMaaS), it was observed that while drivers 
had their cars parked outside the company, many potential users had never used the CMaaS system [38].

For public transportation users such as a bus, the "costs" and "safety" were the determining factors for the modal choice (both 3.13).

In a similar way, we observed that the profile of users who were riding in cars as passengers presented averages that were very similar to public transportation users (except for the "agility" factor that is most valued by car passengers: 3.69 compared to 2.89). This may represent an eventual migration from being public transport users towards hitchhiking as a transport mode (thus, balancing the deficiency presented by the latter), which could contribute to MaaS implementation in any given locality.

\subsection{Multimodality instead of ownership}

Table 2 presents the predisposition to change vehicle ownership (car users) or unwillingness to own a vehicle (non-drivers) due to the associated costs. We analyzed the survey for the percentages of "yes" answers for each statement.

Table 2: Predisposition to use other transport modes instead of cars due to the associated costs.

\begin{tabular}{|c|c|c|}
\hline & Car users & Non-car users \\
\hline & $\%$ & $\%$ \\
\hline \multicolumn{3}{|l|}{ Lower Cost, but... } \\
\hline ...Longer travel times & $33.33 \%$ & $52.97 \%$ \\
\hline ...Less comfort & $55.13 \%$ & $66.21 \%$ \\
\hline ...Less avaliability & $23.08 \%$ & $25.57 \%$ \\
\hline ...Less flexibility & $16.67 \%$ & $28.31 \%$ \\
\hline ...Less convenience & $25.64 \%$ & $21.46 \%$ \\
\hline ...Shared commute & $67.95 \%$ & $89.50 \%$ \\
\hline ...Change of transport mode & $61.54 \%$ & $72.15 \%$ \\
\hline
\end{tabular}

It was observed that except for the affirmative "cost over travel time" for the non-driver group, all other assertions pointed out that cost is not the predominant factor, for both groups. The fact that non-drivers are slightly more vulnerable to price as a result of travel time may have a relationship with the waiting habit that is inherent to other transport means (e.g., bus) rather than a car. Thus, in general, those users who own vehicles are somewhat less costinfluenced than non-drivers.

When asked about a reduction in flexibility, convenience and availability (although this would also lead to a reduction in cost), both groups were not willing to change, and the acceptance rate was low for all categories. The increase in convenience, when there was an increase in cost, presented similar average results; that is, lower acceptance. In this way, we observe that flexibility, availability and comfort are variables that are not only valued by car users [27], but also valued by users of other transportation modes. However, the statements involving sharing and exchange of transport modes showed the opposite results. Acceptance was high for both groups and categories, especially regarding vehicle sharing for non-drivers, which achieved $89.50 \%$ acceptance, linked to reduced costs. This may corroborate the strategy of including hitchhiking as a transport mode (especially with regards to the non-driver group), as a way to complement a possible bottleneck in public 
transportation. In addition, the willingness to have a transport mode exchange for reduced costs is in agreement with the proposal of modal integration within MaaS schemes.

\subsection{Tree-based classification models}

In order to understand the predisposition to use MaaS schemes from both the perspective of car users and non-users, we built two tree-based classification models (one for each group). In both cases, we considered predictor variables: age, sex, income, marital status, study day-time, driver's license possession, distance from their institution, monthly expenses with transportation, commute as a weekly frequency and type of institution (public or private).

Classification trees model a categorical response variable (in our case, a binary variable with the answers Yes and No) as a function of one or more predictor variables, which can be both categorical and numerical. The tree is constructed by repeatedly subdividing the data into two distinct paths per variable. Those divisions are dichotomic, splitting the data into two mutually exclusive groups. The division procedure starts with the "root node," a variable that explains most of the variability in the data. In creating the sequence, the same procedure is applied to the subsequent nodes, until the tree remains reasonably small. To interpret it, the partitions are read from top to bottom, where the left paths indicate that the condition given on each partition (for each variable) has been fulfilled.

Considering that MaaS is a fairly recent concept [24], many of the sampled users might not have been familiar with it. Thus, for tree construction, we used in single statements (that were presented to the respondents) a compilation of features that are inherent to MaaS platforms.

4.3.1 Tree \#1: Predisposition to use Mobility-as-a-Service obtained from private car users As depicted by Fig. 1, in general, there was a predisposition to use MaaS by $69 \%$ of private car users. Five splitting variables were identified: income, weekly commute frequency, lone commutes, day/night study-shifts and transportation expenses.

We observed that the profiled people most likely to use MaaS schemes are commuters with intermediate income rates who use their cars 3 times or less per week (100\% of cases). On the other hand, we observed that commuters with intermediate income rates, with higher frequencies of car usage (superior to 3 times a week) and that are used to commuting alone (especially for a night-shift) present lower adherence and less predisposition towards MaaS schemes (only $17 \%$ of cases).

\subsubsection{Tree \#2: Predisposition to use Mobility-as-a-Service by non-private car users}

As observed in Fig. 2, similar to the results obtained on Tree \#1: in general, non-private car users also presented a high predisposition to use MaaS schemes (69\% of respondents). For this second model, eight splitting variables were identified: 1) distance traveled (as daily average), 2) main transport mode, 3) car purchase intent, 4) gender, 5) age, 6) hitchhiking habits, 7) day/night study or shift, and 8) transportation expenses.

In the case of non-private car users, we observed that those who travel daily between 1 to $4 \mathrm{~km}$, who already own a car (but do not use it as the main means of transport) or those who intend to buy a car and whom have monthly transport expenses of more than 30 euros, present $100 \%$ of the predisposition toward MaaS models. On the other hand, users with monthly transport costs that are less than 30 euros, have intermediate commute distances, who already own a car (or those who intend to buy one), and with commuting habits that predominantly are during the night shift, presented only a $14 \%$ predisposition towards models of MaaS (the most negative profile among the sampled users). 


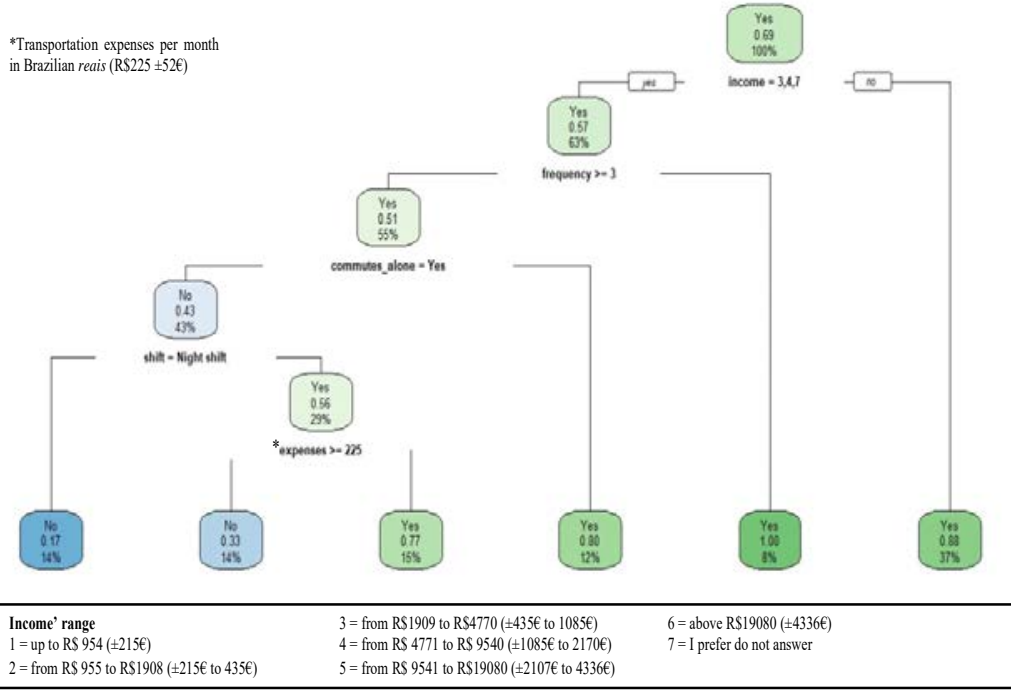

Figure 1: Predisposition to use Mobility-as-a-Service from car-user standpoints.

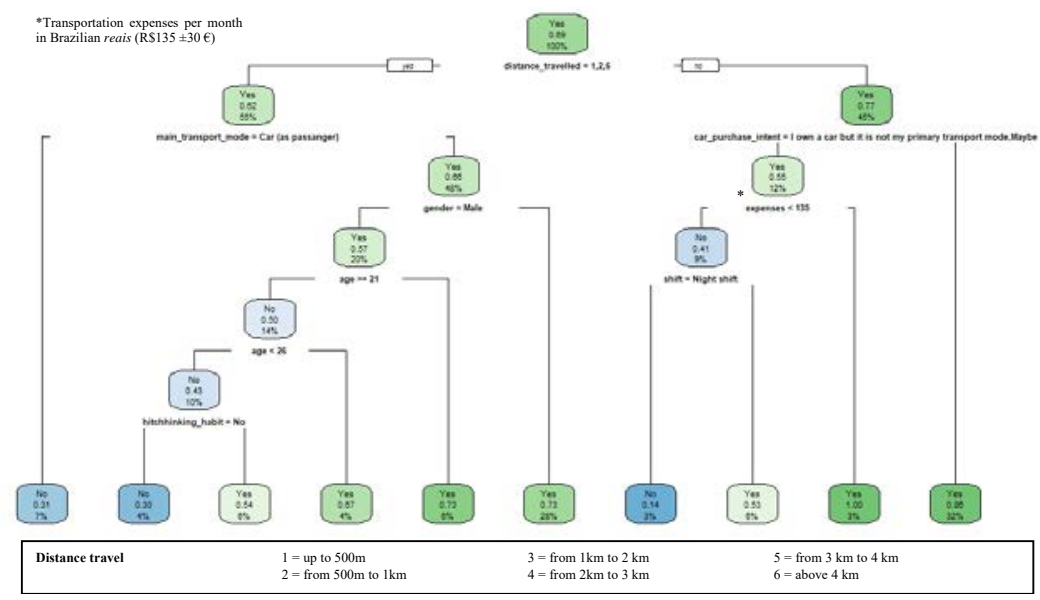

Figure 2: Predisposition to use Mobility-as-a-Service from the standpoint of non-car users.

4.3.3 Predisposition towards Mobility-as-a-Service: drivers and non-drivers' perceptions When it comes to adherence to a MaaS model, we observed that while income is a determinant variable for drivers, for non-drivers one of the most relevant variables is the distance traveled in a commute (rather than income). The night shift for studies had negative influences on both groups of commuters. In the same way, transport expenses influenced both profiles. While higher commute expenses negatively reflected the model for drivers, lower transport expenditures positively influenced the MaaS adherence, regarding non-drivers. This reinforces the greater sensitivity to price of the non-drivers (as previously depicted on the descriptive analyses). 


\section{CONCLUSION}

MaaS seeks to integrate the on-demand commute via bundled offerings of public and private transportation on a single platform; however, as far as we know, MaaS studies have only been carried out in developed countries that have efficient public transport networks [17]. Consequently, we observed that there was a gap with regard to both academic studies and practical deployment of MaaS schemes in developing countries.

By the results obtained in this study, we observed that there is demand and a predisposition towards MaaS schemes among commuters in a developing country. In fact, there is a big challenge to offer seamless transportation in a country where public transportation is inefficient. Nevertheless, we believe that MaaS is modular and adaptable, and can be implemented in any context as long as its users (commuters) perceive value.

The results pointed out by study trees \#1 and \#2 displayed a general $69 \%$ adherence rate from both car users and non-car users towards MaaS. Considering that the average age of our sample was between 22 and 25 years old, we can infer that MaaS use in a developing country does have a positive acceptance from Millennials, corroborating with Jittrapirom et al. [18]. Furthermore, we also found that, when we analyzed isolated characteristics such as: app payment, transport integration, monthly plan, and customization, our results presented a positive probability of substitution for both car users and non-car users. Thus, while income has a predictive impact on car users, the daily distance traveled is the variable that exerts the most influence on non-car users. Factors such as day/night study or shift, transportation expenses, vehicle ownership, gender, age, hitchhiking habits and main transport mode used, had positive and negative impacts on the prediction of predispositions towards MaaS.

We observed that among car users, the commute alternatives that take longer, with less flexibility and availability even when offered at lower costs, were not appealing. Corroborating this, car users pointed out that flexibility, availability and agility are the most important characteristics in the choice of car. Also, status was not signaled as being representative for the choice of a car. In this sense, we believe that a MaaS model that delivers more flexibility, availability and agility may be an option for the car users in a developing country.

Regarding non-car users, we observed that there was a relationship among car as passengers' users and public transportation users. In general, the importance given to the choice of modal hitchhiking (except for the variable "agility"), is similar to that of the public transport user (e.g. comfort, cost, safety and availability). Thus, we believe that the MaaS' hitchhiking modal can be a strategic alternative to address the lack of public transportation efficiency in developing countries. It is worth mentioning that models such as Wazecarpool are already in operation in Brazil, and the adoption of hitchhiking in search of efficiency of car users in urban transportation.

In addition, another modal for MaaS scheme that could be explored in a developing country is the bicycle, especially when considering that this modal is an important part of the MaaS system, especially as a solution for the first and last-mile [39]; yet such a transport mode is still neglected by most of the MaaS studies [31]. We have observed that users of bicycles believe that this modal delivers status, in addition to a perception of care toward health and sustainability. In this sense, we believe that bicycles can strengthen MaaS models not only in developing countries, but in MaaS schemes worldwide.

We also found in our sample that dematerialization phenomena are perceived as positive for urban mobility users. The fact that transportation is dematerialized, and that it is presented as a mobile app, shows there is real perceived value in a considerable group of car users and in non-car users. Peer to peer business models such as Uber, Cabify and others, are already playing an important role towards transport dematerialization, and this can promote a 
reshaping effect on the way commuters relate to transportation means, similar to what has occurred as the music dematerialization phenomenon [32]. It is worth highlighting that transport modes, specifically in MaaS schemes, present other complex distinctions that were not analyzed in this study.

The MaaS concept is still recent and incipient. Therefore, further studies should analyze aspects related to the integration of the Maas ecosystem and actors in it. We believe that the specificities of each MaaS operator will impact its use; however, this study provides the first step towards understanding the predisposition to use MaaS in a developing country.

We suggest that other variables must also be analyzed prior to the insertion of a multimodal digital platform, such as: performance expectancy of the platform measured in spheres of activity and travel time, effort expectancy and social influence [40]. Still, we believe that hitchhiking as a transport mode can contribute to private vehicle efficiency. In this sense, we point out the importance of analyzing the users' perceptions regarding the hitchhiking habit and its motivators, as a strategy for insertion of this modal in a developing country. Another modal that should be deeply analyzed is bicycles, and consumer behavior towards them. Last but not least, it's worth noting that consumer perceptions are temporal cutbacks, so it is necessary to understand the context in which the sample is inserted, prior to making generalizations.

\section{ACKNOWLEDGEMENTS}

This paper would not have been possible without the support and funding of the Laboratoire Génie Industriel in CentraleSupélec, France; the support of the Post-Graduate Program in Administration of Universidade Federal de Lavras (PPGA/UFLA) in Brazil; and the Terrestrial Mobility Laboratory of Universidade Federal de Lavras (LMT/UFLA). We also would like to thank the following Brazilian founding agencies: Coordenação de Aperfeiçoamento de Pessoal de Nível Superior (CAPES) and Conselho Nacional de Desenvolvimento Científico e Tecnológico (CNPq).

\section{REFERENCES}

[1] Urry, J., The "system" of automobility. Theory, Culture \& Society, 21(4-5), pp. 2539, 2004.

[2] Schuppan, J., Kettner, S., Delatte, A. \& Schwedes, O., Urban multimodal travel behaviour: towards mobility without a private car. Transportation Research Procedia, 4, pp. 553-556, 2014.

[3] Epprecht, N., Von Wirth, T., Stünzi, C. \& Blumer, Y.B., Anticipating transitions beyond the current mobility regimes: How acceptability matters. Futures, 60, pp. 3040, 2007.

[4] Stern, N. \& Stern, N.H., The Economics of Climate Change: The Stern Review, Cambridge University Press: Boston, 2007.

[5] Cao, Y. \& Wang, N., Toward efficient electric-vehicle charging using VANET-based information dissemination. IEEE Transactions on Vehicular Technology, 66(4), pp. 2886-2901, 2017.

[6] Ambrosino, G., Nelson, J.D., Boero, M. \& Pettinelli, I., Enabling intermodal urban transport through complementary services: From Flexible Mobility Services to the Shared Use Mobility Agency. Research in Transportation Economics, 59, pp. 179$184,2016$.

[7] Fishman, E., Washington, S. \& Haworth, N., Bike share's impact on car use: evidence from the United States, Great Britain and Australia. Transportation Research, pp. 1320, 2014. 
[8] Martin, E., Shaheen, S.A. \& Lidicker, J., Impact of carsharing on household vehicle holdings: Results from North American shared-use vehicle survey. Transportation Research Record, 2143(1), pp. 150-158, 2010.

[9] Wong, Y.Z., Hensher, D.A. \& Mulley, C., Emerging transport technologies and the modal efficiency framework: A case for mobility as a service (MaaS). Presented at 15th International Conference on Competition and Ownership in Land Passenger Transport (Thredbo 15), Stockholm, Sweden, 2017.

[10] Jittrapirom, P., Caiati, V., Feneri, A., Ebrahimigharehbaghi, S., Alonso-González, M.J. \& Narayan, J., Mobility as a Service: A critical review of definitions, assessments of schemes and key challenges. Urban Planning, 2(2), pp. 13-25, 2017.

[11] Mulley, C., Mobility as a Service (MaaS) - does it have critical mass? Transport Reviews, 37(3), pp. 247-251, 2017.

[12] Kamargianni, M., Li, W., Matyas, M. \& Schäfer, A., A critical review of new mobility services for urban transport. Transportation Research Procedia, 14, pp. 3294-3303, 2016.

[13] Hensher, D.A., Future bus transport contracts under a mobility as a service (MaaS) regime in the digital age: Are they likely to change? Transportation Research Part A, 98, pp. 86-96, 2017.

[14] Matyas, M. \& Kamargianni, M., A stated preference experiments for Mobility-as-aService plans. Models and Technologies for Intelligent Transportation Systems (MTITS), 2017 5th IEEE International Conference, pp. 738-743, 2017.

[15] Datson, J., Mobility as a Service: Exploring the opportunity for Mobility as a Service in the UK. Report by Transport Systems Catapult, p. 7, 2016. https://ts.catapult.org.uk/ wp-content/uploads/2016/07/Mobility-as-a-Service_Exploring-the-Opportunity-forMaaS-in-the-UK-Web.pdf. Accessed on: 20 Aug. 2018.

[16] Lyons, G., Hammond, P. \& Mackay, K., The importance of user perspective in the evolution of MaaS. Transportation Research Part A: Policy and Practice, 121, pp. 22 36, 2019.

[17] Antonialli, F., Business Platforms for Automated Driving Systems: A Product-Service System Approach for Mobility as a Service, 2018. Doctoral dissertation, retrieved from repositório UFLA.

[18] Jittrapirom, P., Marchau, V., Van der Heijden, R. \& Meurs, H., Future implementation of Mobility as a Service (MaaS): Results of an international Delphi study. Travel Behaviour and Society, 2018.

[19] Dupuy, G., "Cities and automobile dependence" revisité: Les contrariétés de la densité, Revue d'Economie Régionale et Urbaine, I, pp. 141-156, 2002.

[20] Vasconcellos, E.A., Mobilidade cotidiana, segregação urbana e exclusão. Balbim, R., Krause, C. \& Linke, C.C. (orgs.), Cidade e movimento: mobilidades e interações no desenvolvimento urbano. Ipea: Brasilia, ITDP, p. 326, 2016.

[21] Brito, S.V.A., O novo conceito de mobilidade urbana, diante dos limites do planeta e sua relação com as políticas de mudanças climáticas, ESDHC: Dissertação de Mestrado, Belo Horizonte, 2013.

[22] Fournier, G., The new mobility paradigm: Transformation of value chain and value proposition through innovations. The Automobile Revolution, Springer: Cham, pp. 2147, 2017.

[23] Saddi, F., Esses são os 3 pilares para a mobilidade do futuro, de acordo com especialista. StatSe, 2018. https://conteudo.startse.com.br/startups/mobtech/taina/ mobility-day-fernando-saddi-easy-carros/. Accessed on: 10 Aug. 2018. 
[24] Hietanen, S., "Mobility as a Service" The new transport model? Eurotransport, 12(2), pp. 2-4, 2014.

[25] Karlsson, I.M., Sochor, J. \& Strömberg, H., Developing the "Service" in Mobility as a Service: Experiences from a field trial of an innovative travel brokerage. Transportation Research Procedia, 14, pp. 3265-3273, 2016.

[26] Steg, L., Car use: Lust and must. Instrumental, symbolic and affective motives for car use. Transportation Research Part A: Policy and Practice, 39(2-3), pp. 147-162, 2005.

[27] Kamau, J., Ahmed, A., Rebeiro, A., Kitaoka, H., Okajima, H. \& Ripon, Z.H., Demand responsive mobility as a service. 2016 IEEE International Conference on Systems, Man, and Cybernetics (SMC), pp. 001741-001746, 2016.

[28] Flügge, B., (ed.). Smart Mobility-Connecting Everyone: Trends, Concepts and Best Practices, Springer, 2017.

[29] Delbosc, A., McDonald, N., Stokes, G., Lucas, K., Circella, G. \& Lee, Y., Millennials in cities: Comparing travel behaviour trends across six case study regions. Cities, $\mathbf{9 0}$, pp. 1-14, 2019.

[30] Parker, G.G., Van Alstyne, M., Choudary, S.P. \& Foster, J., Platform Revolution: How Networked Markets are Transforming the Economy and How to Make Them Work for You, WW Norton: New York, p. 352, 2016.

[31] Utriainen, R. \& Pöllänen, M., Review on mobility as a service in scientific publications. Research in Transportation Business \& Management, 2018.

[32] Magaudda, P., When materiality "bites back": Digital music consumption practices in the age of dematerialization. Journal of Consumer Culture, 11(1), pp. 15-36, 2011.

[33] Strömberg, H., Rexfelt, O., Karlsson, I.M. \& Sochor, J., Trying on change-Trialability as a change moderator for sustainable travel behaviour. Travel Behaviour and Society, 4, pp. 60-68, 2016.

[34] Aaker, D.A., Kumar, V. \& Day, G.S., Pesquisa de Marketing, Atlas: São Paulo, 2001.

[35] Malhotra, N., Pesquisa de Marketing: Uma Orientação Aplicada, Bookman: Porto Alegre, Brazil, 2001.

[36] Hair Jr., J.F., Black, W.C., Babin, B.J., Anderson, R.E. \& Tatham, R.L., Análise MultiAnálise Multivariada de Dados, 6th ed., Bookman Editoria: Porto Alegre, 2009.

[37] Breiman, L., Friedman, J.H., Olshen, R.A. \& Stone, C.J., Classification and Regression Trees, Wadsworth, 1984.

[38] Hesselgren, M., Sjöman, M. \& Pernestål, A., Understanding user practices in mobility service systems: Results from studying large scale corporate MaaS in practice. Travel Behaviour and Society, 2019.

[39] Nikitas, A., Understanding bike-sharing acceptability and expected usage patterns in the context of a small city novel to the concept: A story of "Greek Drama". Transportation Research part F: Traffic Psychology and Behaviour, 56, pp. 306-321, 2018.

[40] Dantan, S., Bulteau, J. \& Nicolaï, I., Enhancing sustainable mobility through a multimodal platform: would travelers pay for it? International Journal of Sustainable Development, 20(1-2), pp. 33-55, 2017. 